\title{
Evaluation of Metabolic Syndrome and Its Associated Risk Factors in Type 2 Diabetes: A Descriptive Cross-Sectional Study at the Komfo Anokye Teaching Hospital, Kumasi, Ghana
}

\author{
Francis Agyemang-Yeboah, ${ }^{1}$ Benjamin Ackon Jnr. Eghan, ${ }^{2}$ Max Efui Annani-Akollor $\mathbb{D},{ }^{1}$ \\ Eliezer Togbe, ${ }^{3}$ Sampson Donkor ${ }^{\mathbb{D}},{ }^{1}$ and Bright Oppong Afranie ${ }^{1}$ \\ ${ }^{1}$ Department of Molecular Medicine, School of Medical Sciences, Kwame Nkrumah University of Science and Technology (KNUST), \\ Kumasi, Ghana \\ ${ }^{2}$ Medicine Department, School of Medical Sciences, Kwame Nkrumah University of Science and Technology (KNUST), Kumasi, Ghana \\ ${ }^{3}$ Department of Medical Laboratory Technology, Faculty of Allied Health Sciences, \\ Kwame Nkrumah University of Science and Technology (KNUST), Kumasi, Ghana
}

Correspondence should be addressed to Sampson Donkor; sampsondonkor08@gmail.com

Received 12 January 2019; Accepted 18 April 2019; Published 2 May 2019

Academic Editor: Andrei Surguchov

Copyright (C) 2019 Francis Agyemang-Yeboah et al. This is an open access article distributed under the Creative Commons Attribution License, which permits unrestricted use, distribution, and reproduction in any medium, provided the original work is properly cited.

\begin{abstract}
Background. Metabolic syndrome (MS) is a collection of cardiovascular risk factors comprising insulin resistance, dyslipidemia, obesity, and hypertension, which may cause further complications in diabetes. Although metabolic syndrome (MS) is increasing in incidence in diabetics and leading to significant cardiovascular diseases and mortality, there is dearth of data in Ghana. This study investigated metabolic syndrome, its prevalence, and its associated risk factors in type 2 diabetes at the Komfo Anokye Teaching Hospital, Kumasi, Ghana. Methods. The study involved 405 diabetic patients attending the Diabetic Clinic of the Komfo Anokye Teaching Hospital (KATH) Kumasi, in the Ashanti Region of Ghana. A well-structured questionnaire was used to obtain demographic background such as their age and gender. Anthropometric measurements were obtained using the Body Composition Monitor (Omron ${ }^{\circledR} 500$, Germany) which generated digital results on a screen and also by manual methods. Fasting venous blood was collected for the measurement of biochemical parameters comprising fasting plasma glucose (FPG), glycated haemoglobin (HbAlc), high density lipoprotein cholesterol (HDL-c), and triglyceride (TG). Metabolic syndrome was defined according to the National Cholesterol Education Program Adult Treatment Panel III (NCEP ATP III). Results. Out of the total of 405 participants, 81 were males and 324 were females, and the estimated mean age was $58.5 \pm 9.9$ years. The female patients exhibited higher mean waist circumference (WC) and mean hip circumference (HC) as well as an approximately higher body mass index than males (28.3 $\pm 5.1,26.5 \pm 4.2$ for the female and male respectively). Overall, the prevalence of metabolic syndrome observed among the study population was $90.6 \%$. Conclusions. The prevalence of metabolic syndrome observed among the study population was $90.6 \%$, with a higher percentage in females than males. High triglyceride levels and high waist circumference were the main risk factors for MS in the diabetic population.
\end{abstract}

\section{Background}

Metabolic syndrome (MS) is a combination of clinical and biological abnormalities which confers greater risk of type 2 diabetes (T2DM), cardiovascular disease (CVD) [1], and liver diseases [2]. A study in Ghana on the prevalence of MS in type 2 diabetes mellitus patients revealed an estimate of $58 \%$ [3]. The different parameters that comprise MS were initially described by Reaven in 1988 in what was called "syndrome X" [4]. These include abdominal obesity, higher-than-optimal plasma pressure, disorders of glucose metabolism, and abnormal lipid profile [4].

The underlying feature of all these abnormalities, though still debated, seems to be insulin resistance. Independent of any abnormalities of glucose metabolism, individuals with type 2 diabetes are at increased risk of MS [5, 6]. When 
diabetes mellitus and MS occur simultaneously the chances of cardiovascular risk and Chronic Kidney Disease (CKD) increase [6].

Prevalence studies of MS that have been conducted in West Africa, especially among Ghanaian diabetic patients, are few [7]. This study therefore evaluated metabolic syndrome in type 2 diabetes and the risk factors associated with it. It has been documented in several large epidemiology cohort studies that obesity and other indicators of metabolic syndrome are associated with cardiovascular outcomes in adults, such as cerebrovascular disease, myocardial infarction, and sudden death [8-10]. With the increasing mortality cases recorded among diabetics, identifying risk factors which predispose diabetic patients to MS may offer opportunities to modify lifestyle and develop therapeutic regimens where necessary to prevent further complications [11].

\section{Methods}

2.1. Study Design and Setting. This hospital-based crosssectional study involved 405 diabetic patients attending the Diabetic Clinic of the Komfo Anokye Teaching Hospital (KATH) Kumasi, in the Ashanti Region of Ghana. It is located in Kumasi, the Regional capital of the Ashanti Region in Ghana with a total projected population of 4,780,380 (Ghana Statistical Service, 2010). KATH is a major Teaching Hospital and it is positioned in the middle belt of Ghana. It has over 1000 bed capacity. The relatively good road network and the cosmopolitan nature of Kumasi make the hospital accessible to all other areas.

2.2. Study Population. Using a simple random sampling technique, 405 patients visiting the diabetic clinic at KATH were recruited for the study. Using a prevalence of T2DM of $4 \%$ [12] in urban areas in Ghana, the Cochran's formula [13] was used to calculate the minimum population size required for this work and was 373 participants. However, to accommodate a nonresponse rate of $10 \%$ and stronger statistical power and effect size, the sample size was projected to 405 .

Pregnant women, urinary tract infection (UTI) patients, and patients with other diagnosed chronic conditions apart from diabetes were excluded from this study. Written consent was obtained from all participants by explaining to them the aim of the project and their freedom to either participate or not, in their native language (Twi). Those literates read and voluntarily appended their signatures and the illiterates applied thumbprints to the consent forms. The study was approved by the Committees on Human Research Publication and Ethics (CHRPE) of the Kwame Nkrumah University of Science and Technology (KNUST) and the Komfo Anokye Teaching Hospital (KATH), Kumasi.

\subsection{Questionnaire Administration and Data Collection. A} well-structured questionnaire was administered to all participants by qualified research assistants. Items in the questionnaire included demographic background, educational level, socioeconomic status, and past and current drug history. Fasting venous blood was collected for the measurement of some biochemical parameters comprising fasting plasma glucose (FPG), high density lipoprotein cholesterol (HDL-c), and triglyceride using the Vitalab Flexor E (Vital Scientific BV, Spankeren/Dieren, The Netherlands) analyzer as well as glycated haemoglobin (HbAlc) using Variant II (Bio Rad, Hercules, CA, USA) analyzer.

2.4. Anthropometric Measurement. Anthropometric measurements were obtained using the Body Composition Monitor (Omron ${ }^{\circledR}$ 500, Germany) which employs bioelectric impedance (BIA) and by manual methods. A Digital Stadiometer (seca 213) was used to measure height $(\mathrm{cm})$. Furthermore, the waist and hip circumferences were each measured to the nearest $0.1 \mathrm{~cm}$ by a tape measure, and the waist-to-hip ratio (WHR) was calculated as $\mathrm{Wcm} / \mathrm{Hcm}$. The Body Composition Monitor generated values for body fat percentage and calculated the BMI (Body Mass Index) from weight registered by the instrument and height (converted to metres) values manually entered.

2.5. Determination of Metabolic Syndrome. Metabolic syndrome was defined according to the modified National Cholesterol Education Program Adult Treatment Panel III (NCEP ATP III), since this classification has been proven to be more accurate $[14,15]$. The modified NCEP, ATP III definition required at least three of the followings: (i) waist circumference $(>90 \mathrm{~cm}$ in men and $>80 \mathrm{~cm}$ in women for Asians), (ii) high triglyceride $\geq 150 \mathrm{mg} / \mathrm{dl}$ ( $1.7 \mathrm{mmol} / \mathrm{l}$ ), (iii) low high density lipoprotein cholesterol (HDL-c) $<40 \mathrm{mg} / \mathrm{dl}$ $(1.03 \mathrm{mmol} / \mathrm{l})$ in men and $<50 \mathrm{mg} / \mathrm{dl}(1.29 \mathrm{mmol} / \mathrm{l})$ in women, (iv) blood pressure ( $\geq 130 / 85 \mathrm{mmHg}$ or current antihypertensive medication), and (v) fasting plasma glucose $\geq 100 \mathrm{mg} / \mathrm{dl}$ $(\geq 5.6 \mathrm{mmol} / \mathrm{l})$.

2.6. Statistical Analyses. Data was analyzed using GraphPad Prism version 5.00 and SPSS version 20 (SPSS Inc., Chicago, IL, USA). The results were expressed as mean \pm SD. Unpaired t-test and one way analysis of variance (ANOVA) were used to compare mean values of continuous variables. Differences were considered to be statistically significant at $p$ value less than 0.05 . Metabolic syndrome was defined according to the National Cholesterol Education Program Adult Treatment Panel III (NCEP ATP III). The receiver operating characteristic (ROC) curve was used to establish the sensitivity, specificity, and the area under curve (AUC) to assess the accuracy and cut-off of selected indicators for MS.

\section{Results}

The estimated average age was $58.5 \pm 9.9$ years. Though the males were on average slightly younger than the females, the gender age difference was not statistically significant $(p=0.554)$. Gender differences in the average levels of fasting plasma glucose FPG, percentage glycated haemoglobin (HbAlc (\%)) and percentage individuals with HbAlc greater than 7 percent were not significant $(\mathrm{p}=0.234,0.643$ and 0.551 respectively) (Table 1 ).

In general, the anthropometric indices of the male subjects in this study were found to be significantly different from 
TABLE 1: Baseline characteristics of the study population stratified by sex.

\begin{tabular}{lccc}
\hline Variables & $\begin{array}{c}\text { TOTAL } \\
(\mathrm{n}=405)\end{array}$ & $\begin{array}{c}\text { MALE } \\
(\mathrm{n}=81)\end{array}$ & $\begin{array}{c}\text { FEMALE } \\
(\mathrm{n}=324)\end{array}$ \\
\hline Age (years) & $58.5 \pm 9.9$ & $57.9 \pm 10.4$ & $58.6 \pm 9.8$ \\
Duration of diabetes (years) & $6.4 \pm 5.4$ & $6.1 \pm 5.3$ & $6.5 \pm 5.5$ \\
FPG (mmol L ${ }^{-1}$ ) & $9.3 \pm 4.1$ & $9.7 \pm 5.2$ & $9.1 \pm 3.7$ \\
HbAlc $(\%)$ & $7.1 \pm 1.4$ & $7.2 \pm 1.4$ & $7.1 \pm 1.4$ \\
HbAlc $>7 \%$ & $198(48.9)$ & $42(51.9)$ & $156(48.1)$ \\
\hline
\end{tabular}

Data are presented as mean \pm SD. FPG: Fasting Plasma Glucose, HbAlc: glycated haemoglobin.

TABLE 2: Anthropometrics of the study population stratified by gender.

\begin{tabular}{lcccc}
\hline Variables & TOTAL & MALE & FEMALE \\
$(\mathrm{n}=405)$ & $(\mathrm{n}=81)$ & p-value \\
\hline Weight $(\mathrm{kg})$ & $70.2 \pm 14.0$ & $73.7 \pm 12.5$ & $69.3 \pm 14.3$ & 0.012 \\
Height $(\mathrm{m})$ & $1.6 \pm 0.1$ & $1.7 \pm 0.1$ & $1.6 \pm 0.1$ & $28.3 \pm 5.1$ \\
BMI $\left(\mathrm{kg} / \mathrm{m}^{2}\right)$ & $27.9 \pm 5.0$ & $26.5 \pm 4.2$ & $101.4 \pm 12.3$ & 0.004 \\
WC $(\mathrm{cm})$ & $100.0 \pm 12.2$ & $98.3 \pm 11.5$ & $104.6 \pm 9.9$ & 0.040 \\
HC $(\mathrm{cm})$ & $103.9 \pm 9.7$ & $101.2 \pm 8.3$ & $1.0 \pm 0.1$ & 0.005 \\
WHR & $1.0 \pm 0.1$ & $1.0 \pm 0.1$ & 0.924 \\
\hline
\end{tabular}

Data are presented as mean \pm SD. BMI: body mass index; WC: waist circumference; HC: hip circumference; WHR: waist to hip ratio.

their female counterparts. Waist-to-hip ratio (WHR) was the only anthropometric measurement that was not significant in terms of gender difference $(p=0.924)$. All other measured parameters of weight, height, BMI, WC, and HC showed statistical differences when stratified by gender. The males exhibited higher means of weight and height than females. However, the females had higher means of BMI, WC, and HC than the males (Table 2).

It was observed from this study that female diabetic patients were more prone to presenting with abdominal obesity and reduced levels of high density lipoprotein cholesterol (HDL-c) than their male counterparts. However, gender differences in raised fasting plasma glucose and triglyceride were not statistically significant (Figure 1).

In general the prevalence of metabolic syndrome observed among the study population was $90.6 \%$. However, the MS condition among female participants (94.1\%) was significantly higher than that of their male counterparts (76.5\%) with $\mathrm{p}$ less than 0.0001. A significantly higher proportion of males exhibited two components of metabolic syndrome compared to the female. However, the reverse was observed with participants presenting with more than two components of metabolic syndrome, where the female proportion was significantly higher (Figure 2).

It was observed that all the selected demographic, biochemical, and anthropometric indices used in this study could significantly serve as diagnostic indicators of metabolic syndrome at various cut-off points and accuracies (Table 3). The more accurate variables with their ability to predict metabolic syndrome defined by the NCEP ATP III criteria were triglyceride, $\mathrm{BMI}$, and waist circumference (AUC $=0.879,0.811$, and 0.874 , respectively). Their respective cut-off, sensitivity, and specificity are represented in Table 3 as well as the confidence interval. Participants with triglyceride levels greater than $1.71 \mu \mathrm{mol} \mathrm{L1}$ were at a higher risk of being positive for metabolic syndrome as well as those with waist circumference $>95 \mathrm{~cm}$ and $\mathrm{BMI}>24.8 \mathrm{~kg} \mathrm{~m}-2$. Moreover, study participants with HDL-c less than or equal to $0.95 \mathrm{mmol} \mathrm{L-1}$ were $100 \%$ specific for metabolic syndrome.

Majority of the respondents had basic education, with the female showing a significantly higher level of no formal education than the males. The number of males that had obtained tertiary education at the time of the study was significantly higher than the females (Figure 3(a)). Greater body fat deposition was observed among the female participants with about seventy-three percent of them exhibiting high to very high body fat percentage (Figure 3(b)). Serum hypertriglyceridaemia was $29.88 \%$ among the study participants (Figure 3(c)). Most of the females enrolled for this study exhibited high central adiposity and hence fell within the high central obesity risk (WHR) group (Figure 3(d)).

Using the various cut-off point for the indices assessed as references in univariate multiple regression analysis to estimate the risk factor for metabolic syndrome among the study population, age above fifty-three (53) years and duration of disease greater than five (5) years were found not be significant predisposing factors for metabolic syndrome (Table 4). However, the female subjects had an approximately five (5) times risk of developing metabolic syndrome compared to their male counterparts. Among the biochemical diagnostic markers, an HbAlc level of greater than 5.43 percent increased the risk of metabolic syndrome approximately four (4) folds in the study subjects. Triglyceride levels above $1.71 \mathrm{mmol} / \mathrm{L}$ were the most indicative risk factor for a diabetic patient to develop metabolic syndrome. Thus subjects with this level of triglyceride had 82 times risk of presenting the condition compared to those with lower levels. The body's anthropometric characteristics of the patients were found 


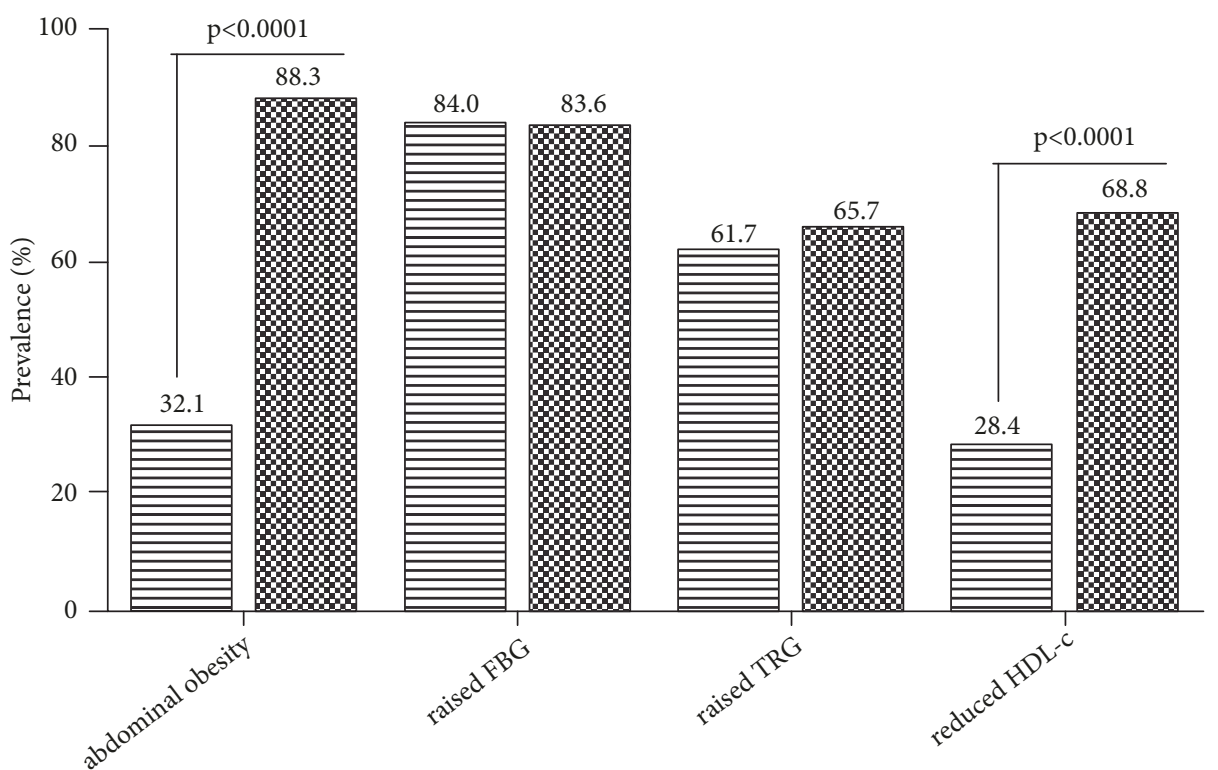

metabolic syndrome risk factors (NCEP-ATP III)

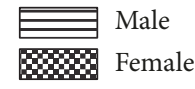

FIGURE 1: Prevalence of selected risk factors for metabolic syndrome stratified by gender.

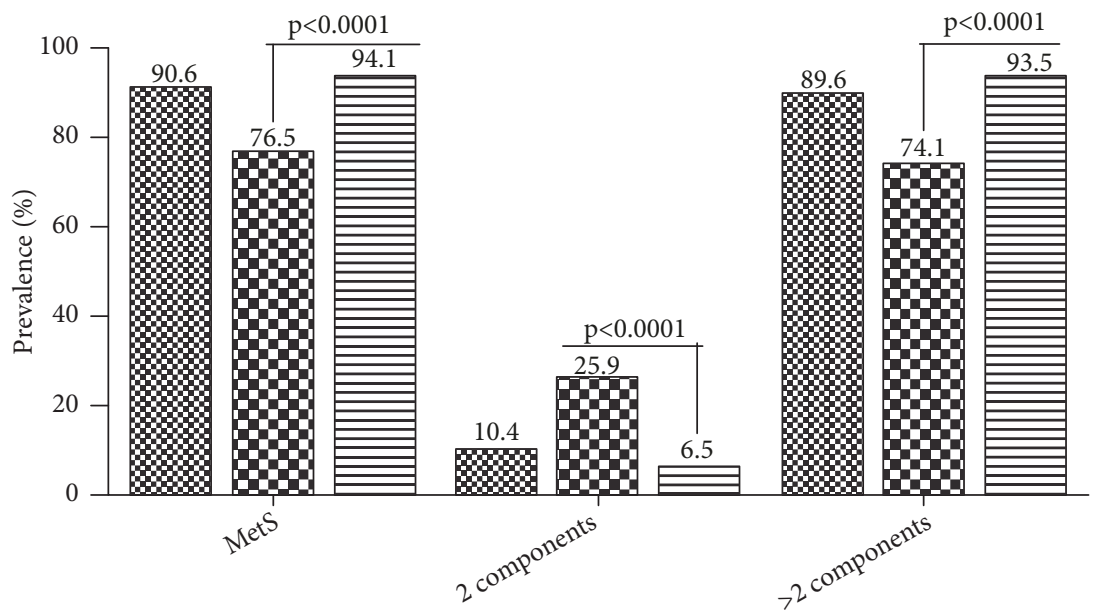

metabolic syndrome and components (NCEP-ATP III)

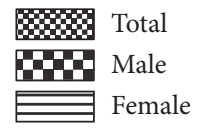

FIgURE 2: Prevalence of metabolic syndrome and its components among the study population with further stratification by gender.

to be significant risk determinants in the development of metabolic syndrome among the participants, with a risk index ranging four folds for waist-to-hip ratio greater than 0.958 to about twenty-four folds for waist circumference above $95 \mathrm{~cm}$. (Table 4).

\section{Discussion}

The estimated mean age was $58.5 \pm 9.9$ years. Though the males were on average slightly younger than the females, the gender age difference was not statistically significant $(p=0.554)$ (Table 1). In general, the anthropometric indices of the participants in this study were found to be significantly different in terms of gender, with the exception of waist-to-hip ratio which was found not to be significant. The females exhibited a higher mean waist circumference and average hip circumference as well as a higher body mass index $(\mathrm{BMI})$ than males $(28.3 \pm 5.1,26.5 \pm 4.2$ for female and male) (Table 2). Majority of the fat distribution 
TABLE 3: Cut-off values of selected variables and their ability to predict metabolic syndrome defined by the NCEP-ATP III criteria.

\begin{tabular}{|c|c|c|c|c|c|c|}
\hline Variable & Cut-off level & Sensitivity & $95 \% \mathrm{CI}$ & Specificity & $95 \% \mathrm{CI}$ & AUC \\
\hline Age (years) & $>53$ & 70.3 & $65.3-74.9$ & 39.5 & $24.0-56.6$ & 0.504 \\
\hline Duration (years) & $>5$ & 44.1 & $39.0-49.4$ & 68.4 & $51.3-82.5$ & 0.562 \\
\hline FBG $\left(\mathrm{mmol} \mathrm{L}^{-1}\right)$ & $>8.3$ & 48.5 & $43.3-53.7$ & 63.2 & $46.0-78.2$ & 0.543 \\
\hline HbAlc (\%) & $>5.43$ & 91.0 & $87.6-93.7$ & 26.3 & $13.4-43.1$ & 0.592 \\
\hline Triglyceride $\left(\mu \mathrm{mol} \mathrm{L}^{-1}\right)$ & $>1.71$ & 68.9 & $63.9-73.6$ & 97.4 & $86.2-99.9$ & $0.879 *$ \\
\hline $\mathrm{HDL}-\mathrm{c}\left(\mathrm{mmol} \mathrm{L}^{-1}\right)$ & $\leq 0.95$ & 26.4 & $22.0-31.3$ & 100.0 & $90.7-100.0$ & 0.671 \\
\hline $\mathrm{BMI}\left(\mathrm{kg} \mathrm{m}^{-2}\right)$ & $>24.8$ & 76.0 & $71.3-80.3$ & 71.1 & $54.1-84.6$ & $0.811 *$ \\
\hline $\mathrm{WC}(\mathrm{cm})$ & $>95$ & 73.6 & $68.7-78.0$ & 89.5 & $75.2-97.1$ & $0.874 *$ \\
\hline $\mathrm{HC}(\mathrm{cm})$ & $>101$ & 58.9 & $53.6-63.9$ & 86.8 & $71.9-95.6$ & 0.777 \\
\hline WHR & $>0.958$ & 59.1 & $53.9-64.2$ & 76.3 & $59.8-88.6$ & 0.713 \\
\hline
\end{tabular}

HbAlc: glycated haemoglobin; FPG: Fasting Plasma Glucose; BMI: body mass index; WC: waist circumference; HC: hip circumference; WHR: waist to hip ratio; HDL-c: high density lipoprotein cholesterol. Almost all variables were likely to predict MS, with the main being triglyceride*, Waist Circumference* and $\mathrm{BMI} *$.

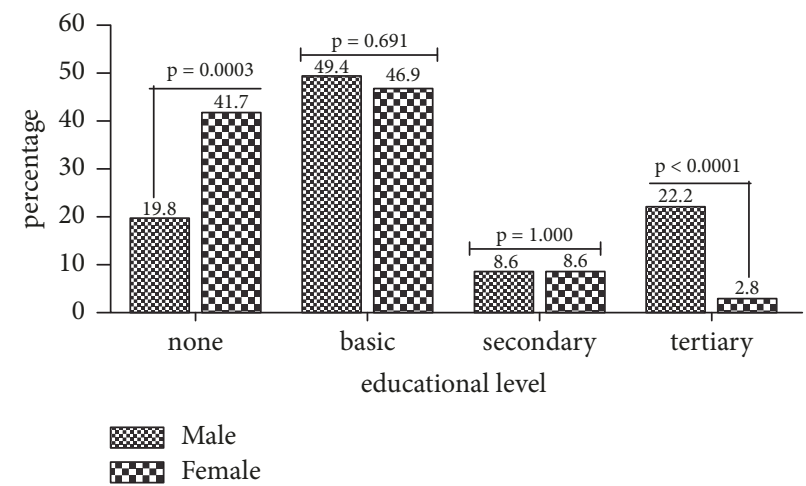

(a)

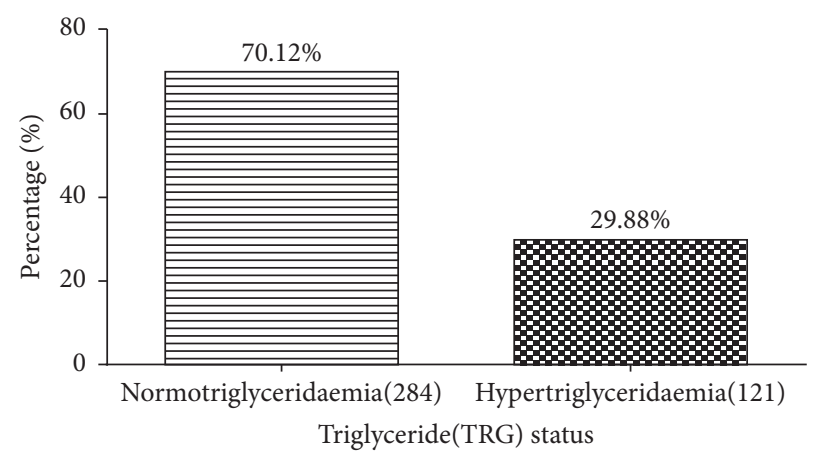

(c)

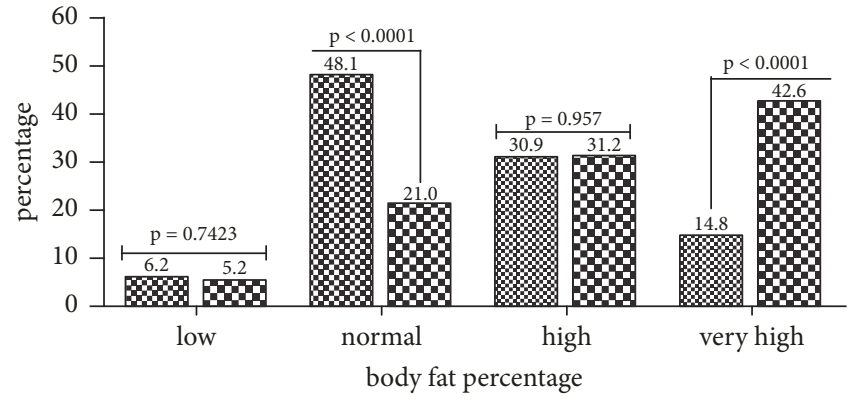

(b)

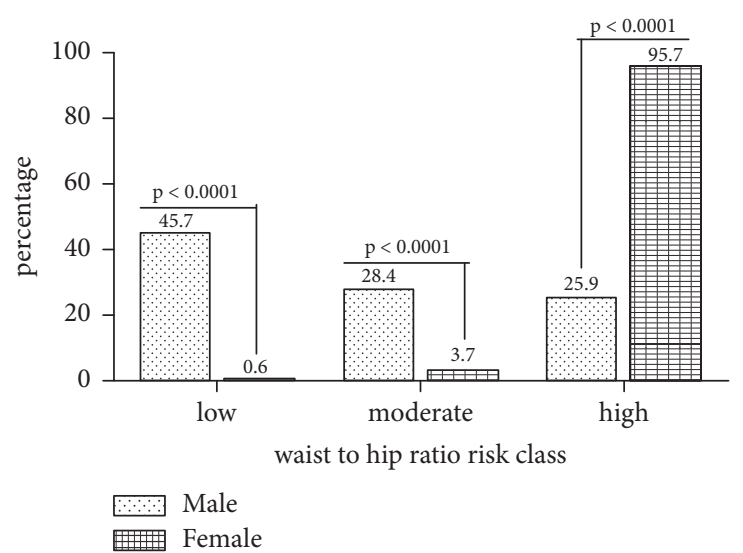

(d)

FIGURE 3: Percentage distribution of the study population by educational level (a), body fat percentage (b), triglyceride status (c), and waistto-hip ratio $(\mathrm{d})$.

markers were significantly higher among the female subjects in this study (Figure 1). It was observed from this study that female diabetic patients were more likely to present with abdominal obesity and reduced levels of high density lipoprotein cholesterol (HDL-c) than their male counterparts (Figure 1). Nevertheless, there were no statistical differences in raised fasting plasma glucose and triglyceride in relation to gender.
A relatively high prevalence of metabolic syndrome (MS) was observed among the study participants. A value of $90.6 \%$ of all participants in this study was classified as presenting with metabolic syndrome using the NCEP ATP III criteria (Figure 2). In earlier works of Titty et al. among type 2 diabetics at Komfo Anokye Teaching Hospital in [16] and Tamale Teaching Hospital in [17], with participants of similar characteristics like the current study, the prevalence of 
TABLE 4: Univariate analysis of the study variables as risk factors for metabolic syndrome in diabetic patients.

\begin{tabular}{lcc}
\hline Variables $($ response $)$ & OR $(95 \% \mathrm{CI})$ & p-value \\
\hline Age $(>53$ years $)$ & $1.5(0.8-2.1)$ & 0.216 \\
Duration $(>5$ years $)$ & $1.7(0.8-3.5)$ & 0.132 \\
Sex $($ female $)$ & $4.9(2.5-9.8)$ & 0.001 \\
FPG $\left(>8.3 \mathrm{mmol} \mathrm{L}^{-1}\right)$ & $1.6(0.8-3.2)$ & 0.174 \\
HBAlc $(>5.43 \%)$ & $3.6(1.6-8.1)$ & 0.002 \\
Triglyceride $\left(>1.71 \mathrm{mmol} \mathrm{L}^{-1}\right)$ & $82.1(11.1-605.9)$ & 0.001 \\
BMI $\left(>24.8 \mathrm{~kg} \mathrm{~m}^{-2}\right)$ & $7.7(3.7-16.1)$ & 0.001 \\
Waist circumference $(>95 \mathrm{~cm})$ & $23.7(8.2-68.4)$ & 0.001 \\
Hip circumference $(>101 \mathrm{~cm})$ & $9.4(3.6-24.7)$ & 0.001 \\
Waist to hip ratio $(>0.958)$ & $4.1(1.9-8.7)$ & 0.001 \\
Body fat percentage $(>32.6)$ & $14.2(5.8-35.1)$ & 0.001 \\
\hline
\end{tabular}

There was a significant relationship between variables and MS with the exception of age, duration of diabetes, and Fasting Plasma Glucose (FPG).

metabolic syndrome among the subjects reported was $55.9 \%$ and $60.3 \%$, respectively. Though our documented prevalence of MS was higher compared to that reported by Titty et al., $[16,17]$, the probable reason may be because he and his colleagues recruited newly diagnosed diabetics of less than 1 year duration where complications such as hypertension and high abdominal circumference had not yet set in. However our results were quite similar to the observation of Kelliny et al., [18] who reported $80 \%$ of metabolic syndrome among diabetics in the Seychelles [18].

Gender differences in health vary according to differential vulnerabilities in men and women [19]. The susceptibility of female population to metabolic syndrome may be attributed to the interplay between sociodemographic factors and the corresponding biological outcomes [20]. The burden of metabolic syndrome was generally significantly higher among the female type 2 diabetics than their male counterparts (Figure 2; 94.43\%, 76.54\% for female and male respectively, $\mathrm{p}<0.0001$ ) in the current study. This is consistent with the reported gender difference in the prevalence of metabolic syndrome and its components among diabetics in the same setting by Titty, Owiredu [16] and Nsiah et al., [3]. Moreover, among other study sample populations and some in different geographical settings, significantly higher female sex difference in the prevalence of metabolic syndrome had also been documented, in Ghana [21-23], Kenya [24], in the Seychelles [18, 25], and in Russia.

Significantly higher number of the female participants presented very high body fat percentage (42.6\%) compared to the males (14.8\%), Figure 3(b). In many areas of sub-Sahara Africa, obesity constitutes an obvious social marker of poor knowledge and misconceptions about lifestyle risk factors which conflict with appropriate prevention and control measures. Furthermore, records of very high prevalence of obesity in urban women in Ghana have been reported by Danquah, Bedu-Addo [26]. According to (Wassink, Van Der Graaf [27, 28]) abdominal obesity is also strongly and independently associated with the incidence of type 2 diabetes. Excess amount and distribution of body adiposity (Figures 1 and 3(b)) have been associated with chronic metabolic diseases such as type 2 diabetes $[29,30]$, cardiovascular diseases [31, 32], and metabolic syndrome [33].

Serum hypertriglyceridaemia was $29.88 \%$ among the patients (Figure 3(c)). Results from a study in Spain confirm that the relationship between triglyceride levels and MS, independent of the presence of peripheral arterial disease, poses high risk for cardiovascular and other disease complications [34]. Though not too sensitive, high triglyceride levels were very specific and the strongest predictor for $\mathrm{MS}$ (AUC $=0.879$; specificity $=97.4 \%$ ) in our study (Table 3 ). As such, patients with triglyceride $>1.71 \mathrm{mmol} / \mathrm{l}(\mathrm{p}=0.001)$ were 82.1 times at risk for metabolic syndrome (Table 4). This may explain why the risk of myocardial infarction is high in metabolic syndrome [35].

Furthermore, the current study revealed significantly lower high waist-to-hip ratio risk among men to women (Figure 3(d)). Arthur et al. [36] identified waist circumference (WC) and waist-to-hip (WHR) but not body mass index (BMI) as significant predictors of metabolic syndrome in Ghanaian postmenopausal women [36]. The current study agreed partly with this finding in that BMI was also used in addition to WC and WHR to predict metabolic syndrome among type 2 diabetics in Ghana in the current study. Using the receiver operating characteristic (ROC) curve analysis, our finding showed similar but higher cut-off for WC $(80.5 \mathrm{~cm}$, versus $95 \mathrm{~cm})$ and WHR (0.84 versus 0.96$)$ compared to the earlier study of Arthur et al. [36], with both variables exhibiting strong prediction for MS (Table 3). The relatively high difference may be explained by the diabetic participants in this current study, and patients with waist circumference greater than $95 \mathrm{~cm}$ were 23.7 times at risk for MS (Table 4).

Educational level attainment has a strong positive effect on health behavior, attitudes, and, consequently, lifestyle choice. In the developing world, particularly Africa and for that matter Ghana disparities exist with gender in the level of educational attainment with higher level of education and older age, i.e., females drop out of school at an earlier age $[22,24,37,38]$. Similarly, the observed gender difference in the distribution of metabolic syndrome in this study (Figure 3(a)) could also be casually attributed to differences in socioeconomic status, attainment of higher education, and the interplay of the two, since significantly more males $(22.2 \%)$ had obtained tertiary education at the time of this study compared to $2.8 \%$ of females who also exhibited a significantly high proportion of participants without any formal education, Figure 3(a). Those with better education were likely to exercise more, eat healthier diets, etc., and this has been said to account for the sex difference in metabolic syndrome documented in Kenya by Kaduka [24].

\section{Conclusions}

The prevalence of metabolic syndrome observed among the study population was $90.6 \%$, with females being likely to be affected than males. Additional risk factors which tend to increase the burden of MS in type 2 diabetes were found to be high plasma triglyceride and high body fat percentage, 
low educational status, and higher anthropometric measurements of waist circumference, hip circumference, waist-tohip ratio, and BMI.

$\begin{array}{ll}\text { Abbreviations } \\ \text { MS/MetS: } & \text { Metabolic Syndrome } \\ \text { FPG: } & \text { Fasting Plasma Glucose } \\ \text { HbAlc: } & \text { Glycated haemoglobin } \\ \text { BMI: } & \text { Body Mass Index } \\ \text { NCEP ATP III: } & \text { National Cholesterol Education Program } \\ & \text { Adult Treatment Panel III } \\ \text { HDL-c: } & \text { High Density Lipoprotein Cholesterol } \\ \text { LDL-c: } & \text { Low Density Lipoprotein Cholesterol } \\ \text { WC: } & \text { Waist Circumference } \\ \text { HC: } & \text { Hip Circumference } \\ \text { WHR: } & \text { Waist-to-Hip Ratio } \\ \text { TG/TRG: } & \text { Triglyceride. }\end{array}$

\section{Data Availability}

The data used to support the findings of this study are available from the corresponding author upon request.

\section{Ethical Approval}

All procedures performed in the study were in accordance with the Helsinki Declaration. The study was approved by the Committees on Human Research Publication and Ethics (CHRPE) of the Kwame Nkrumah University of Science and Technology (KNUST) and the Komfo Anokye Teaching Hospital (KATH), Kumasi.

\section{Consent}

Written consent was obtained from all participants.

\section{Conflicts of Interest}

The authors declare no conflicts of interest.

\section{Authors' Contributions}

Francis Agyemang-Yeboah and Benjamin Ackon Jnr. Eghan planned and established the research idea and objectives. Max Efui Annani-Akollor and Eliezer Togbe participated in designing the analyses and interpreting the findings and also in editing the text. Sampson Donkor and Bright Oppong Afranie analyzed and interpreted the data.

\section{Acknowledgments}

The authors wish to thank the Molecular Medicine Department of the School of Medical Sciences, Kwame Nkrumah University of Science and Technology (KNUST) and the Clinical Biochemistry Department of the Komfo Anokye Teaching Hospital (KATH) for access to their laboratories.

\section{References}

[1] P. Z. Zimmet, D. J. McCarty, and M. P. De Courten, “The global epidemiology of non-insulin-dependent diabetes mellitus and the metabolic syndrome," Journal of Diabetes and its Complications, vol. 11, no. 2, pp. 60-68, 1997.

[2] G. Marchesini, M. Brizi, G. Blanchi et al., "Nonalcoholic fatty liver disease: a feature of the metabolic syndrome," Diabetes, vol. 50, no. 8, pp. 1844-1850, 2001.

[3] K. Nsiah, V. Shang, K. Boateng, and F. Mensah, "Prevalence of metabolic syndrome in type 2 diabetes mellitus patients," International Journal of Applied and Basic Medical Research, vol. 5, no. 2, p. 133, 2015.

[4] G. M. Reaven, "Role of insulin resistance in human disease," Diabetes, vol. 37, no. 12, pp. 1595-1607, 1988.

[5] C. Lorenzo, M. Okoloise, K. Williams, M. P. Stern, and S. M. Haffner, "The metabolic syndrome as predictor of type 2 diabetes: the San Antonio heart study," Diabetes Care, vol. 26, no. 11, pp. 3153-3159, 2003.

[6] V. Xanthakis, J. H. Sung, T. E. Samdarshi et al., "Relations between subclinical disease markers and type 2 diabetes,metabolic syndrome, and incident cardiovascular disease: The Jackson heart study," Diabetes Care, vol. 38, no. 6, Article ID dc142460, pp. 1082-1088, 2015.

[7] C. I. Okafor, "The metabolic syndrome in Africa: current trends," Indian Journal of Endocrinology and Metabolism, vol. 16, no. 1, pp. 56-66, 2012.

[8] A. Halpern, M. C. Mancini, M. E. C. Magalhães et al., "Metabolic syndrome, dyslipidemia, hypertension and type 2 diabetes in youth: from diagnosis to treatment," Diabetology \& Metabolic Syndrome, vol. 2, no. 1, article no. 55, 2010.

[9] K. Nashar and B. M. Egan, "Relationship between chronic kidney disease and metabolic syndrome: Current perspectives," Diabetes, Metabolic Syndrome and Obesity: Targets and Therapy, vol. 7, pp. 421-435, 2014.

[10] R. J. Johnson, P. Stenvinkel, S. L. Martin et al., "Redefining metabolic syndrome as a fat storage condition based on studies of comparative physiology," Obesity, vol. 21, no. 4, pp. 659-664, 2013.

[11] T. Seuring, O. Archangelidi, and M. Suhrcke, "The economic costs of type 2 diabetes: a global systematic review," PharmacoEconomics, vol. 33, no. 8, pp. 811-831, 2015.

[12] A. G. Amoah, S. K. Owusu, and S. Adjei, "Diabetes in Ghana: a community based prevalence study in Greater Accra," Diabetes Research and Clinical Practice, vol. 56, no. 3, pp. 197-205, 2002.

[13] W. G. Cochran, Sampling Techniques, Wiley, New York, NY, USA, 3rd edition, 1977.

[14] S. Chackrewarthy, D. Gunasekera, A. Pathmeswaren et al., "A comparison between revised NCEP ATP III and IDF definitions in diagnosing metabolic syndrome in an urban sri lankan population: the ragama health study," ISRN Endocrinology, vol. 2013, Article ID 320176, 7 pages, 2013.

[15] A. Ahmed, T. E. Khan, T. Yasmeen, S. Awan, and N. Islam, "Metabolic syndrome in Type 2 diabetes: Comparison of WHO, modified ATPIII \& IDF criteria," Journal of the Pakistan Medical Association, vol. 62, no. 8, pp. 569-574, 2012.

[16] F.-V. K. Titty, W. K. B. A. Owiredu, and M. T. Agyei-Frempong, "Prevalence of metabolic syndrome and its individual components among diabetic patients in Ghana," Journal of Biological Sciences, vol. 8, no. 6, pp. 1057-1061, 2008.

[17] F. K. Titty, "Incidence and major metabolic risk factors of metabolic syndrome in type 2 diabetic out-patients visiting 
tamale teaching hospital in Ghana," Ghana Journal of Science, vol. 49, pp. 71-76, 2009.

[18] C. Kelliny, J. William, W. Riesen, F. Paccaud, and P. Bovet, "Metabolic syndrome according to different definitions in a rapidly developing country of the African region," Cardiovascular Diabetology, vol. 7, no. 1, p. 27, 2008.

[19] H.-Y. Shin, M.-H. Shin, and J.-A. Rhee, "Gender differences in the association between self-rated health and hypertension in a Korean adult population," BMC Public Health, vol. 12, article 135, 2012.

[20] A. Hammarström, E. Annandale, and B. Mintzes, "A conceptual muddle: an empirical analysis of the use of 'sex' and 'gender' in 'gender-specific medicine' journals," PLoS ONE, vol. 7, no. 4, p. e34193, 2012.

[21] M. Gyakobo, A. G. B. Amoah, D.-A. Martey-Marbell, and R. C. Snow, "Prevalence of the metabolic syndrome in a rural population in Ghana," BMC Endocrine Disorders, vol. 12, article no. $25,2012$.

[22] W. Owiredu, N. Amidu, E. Gockah-Adapoe, and R. Ephraim, "The prevalence of metabolic syndrome among active sportsmen/sportswomen and sedentary workers in the Kumasi metropolis," Journal of Science and Technology (Ghana), vol. 31, no. 1, 2011.

[23] W. K. B. A. Owiredu, M. S. Adamu, N. Amidu et al., "Obesity and cardiovascular risk factors in a pentecostal population in Kumasi-Ghana," Journal of Medical Sciences (Faisalabad), vol. 8, no. 8, pp. 682-690, 2008.

[24] L. U. Kaduka, Y. Kombe, E. Kenya et al., "Prevalence of metabolic syndrome among an urban population in Kenya," Diabetes Care, vol. 35, no. 4, pp. 887-893, 2012.

[25] O. Sidorenkov, O. Nilssen, T. Brenn, S. Martiushov, V. L. Arkhipovsky, and A. M. Grjibovski, "Prevalence of the metabolic syndrome and its components in Northwest Russia: the Arkhangelsk study," BMC Public Health, vol. 10, no. 1, p. 23, 2010.

[26] I. Danquah, G. Bedu-Addo, K. Terpe et al., "Diabetes mellitus type 2 in urban Ghana: characteristics and associated factors," BMC Public Health, vol. 12, no. 1, article 210, 2012.

[27] A. M. J. Wassink, Y. Van Der Graaf, S. S. Soedamah-Muthu, W. Spiering, and F. L. J. Visseren, "Metabolic syndrome and incidence of type 2 diabetes in patients with manifest vascular disease," Diabetes and Vascular Disease Research, vol. 5, no. 2, pp. 114-122, 2008.

[28] D. R. Faber, Y. van der Graaf, J. Westerink, and F. L. J. Visseren, "Increased visceral adipose tissue mass is associated with increased C-reactive protein in patients with manifest vascular diseases," Atherosclerosis, vol. 212, no. 1, pp. 274-280, 2010.

[29] K. E. Friedl, "Waist circumference threshold values for type 2 diabetes risk," Journal of Diabetes Science and Technology, vol. 3 , no. 4, pp. 761-769, 2009.

[30] M. Sénéchal, M. Rempel, T. A. Duhamel et al., "Fitness is a determinant of the metabolic response to endurance training in adolescents at risk of type 2 diabetes mellitus," Obesity, vol. 23, no. 4, pp. 823-832, 2015.

[31] S. Feller, H. Boeing, and T. Pischon, "Body mass index, waist circumference, and the risk of type 2 diabetes mellitus: implications for routine clinical practice," Deutsches Ärzteblatt International, vol. 107, no. 26, pp. 470-476, 2010.

[32] M. G. Farb and N. Gokce, "Visceral adiposopathy: A vascular perspective," Hormone Molecular Biology and Clinical Investigation, vol. 21, no. 2, pp. 125-136, 2015.
[33] S. R. Kim, J. H. Yoo, H. C. Song et al., "Relationship of visceral and subcutaneous adiposity with renal function in people with type 2 diabetes mellitus," Nephrology Dialysis Transplantation, vol. 26, no. 11, pp. 3550-3555, 2011.

[34] J. Rioja, T. Moreno, I. Coca, M. Jiménez-Villodres, A. Rodríguez-Morata, and P. Valdivielso, "Preliminary analysis of the relationship between peripheral arterial disease and other atherosclerosis markers and diabetic nephropathy," Clinica $e$ Investigacion en Arteriosclerosis, vol. 26, no. 5, pp. 229-235, 2014.

[35] J. K. Ninomiya, G. L'Italien, M. H. Criqui, J. L. Whyte, A. Gamst, and R. S. Chen, "Association of the metabolic syndrome with history of myocardial infarction and stroke in the third national health and nutrition examination survey," Circulation, vol. 109, no. 1, pp. 42-46, 2004.

[36] F. K. N. Arthur, M. Adu-Frimpong, J. Osei-Yeboah, F. O. Mensah, and L. Owusu, "Prediction of metabolic syndrome among postmenopausal Ghanaian women using obesity and atherogenic markers," Lipids in Health and Disease, vol. 11, no. 1, p. 101, 2012.

[37] A. G. B. Amoah, "Sociodemographic variations in obesity among Ghanaian adults," Public Health Nutrition, vol. 6, no. 8, pp. 751-757, 2003.

[38] C. E. Ezenwaka, O. Okoye, C. Esonwune et al., "High prevalence of abdominal obesity increases the risk of the metabolic syndrome in Nigerian type 2 diabetes patients: Using the international diabetes federation worldwide definition," Metabolic Syndrome and Related Disorders, vol. 12, no. 5, pp. 277-282, 2014. 


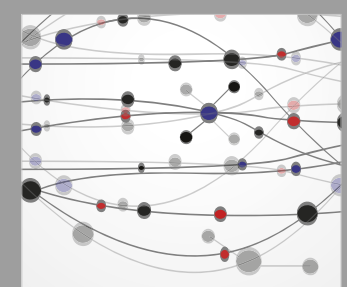

The Scientific World Journal
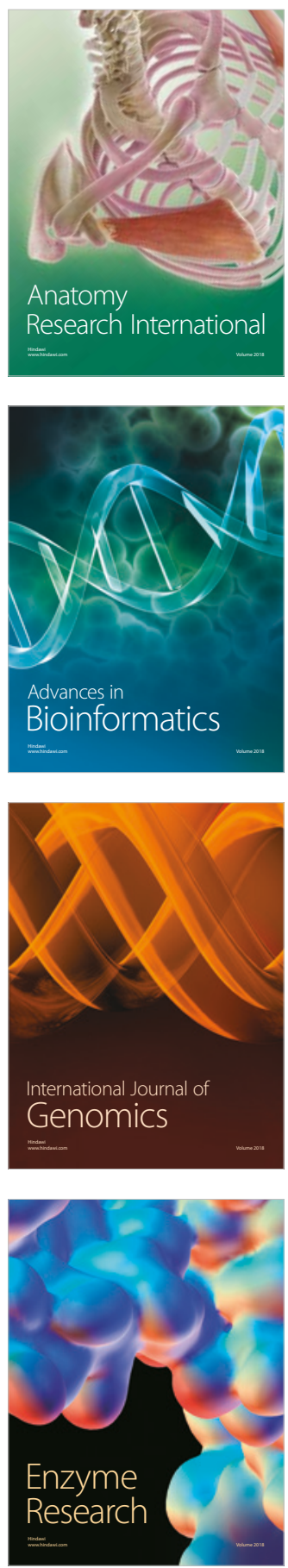
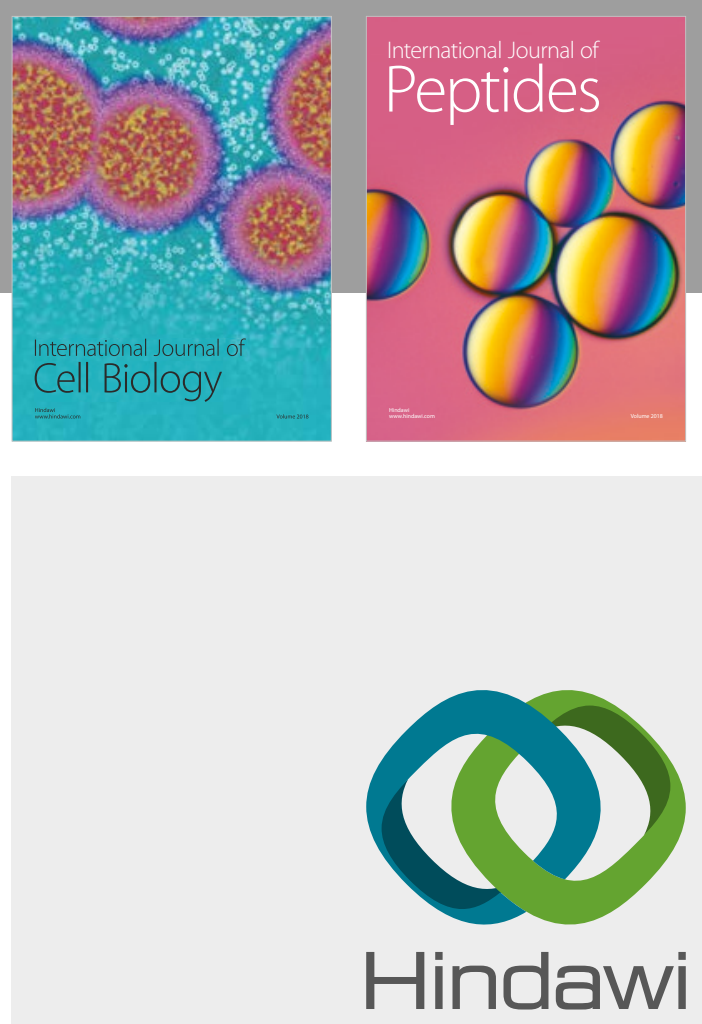

Submit your manuscripts at

www.hindawi.com
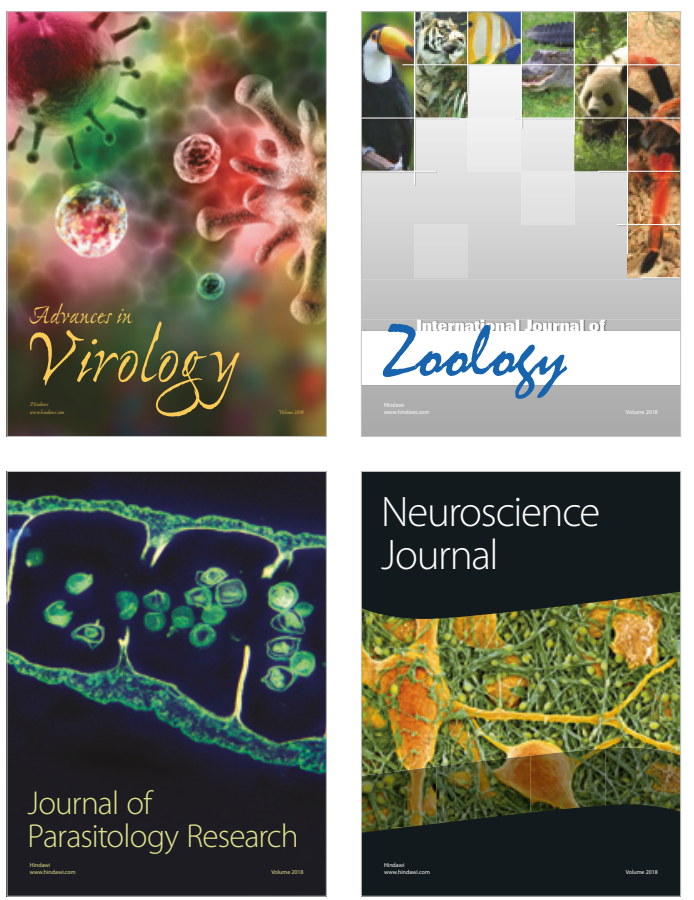
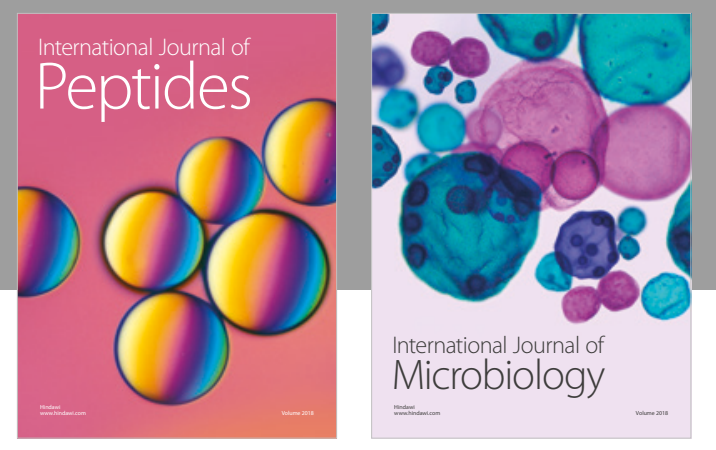

nternational Journal of Microbiology
Journal of
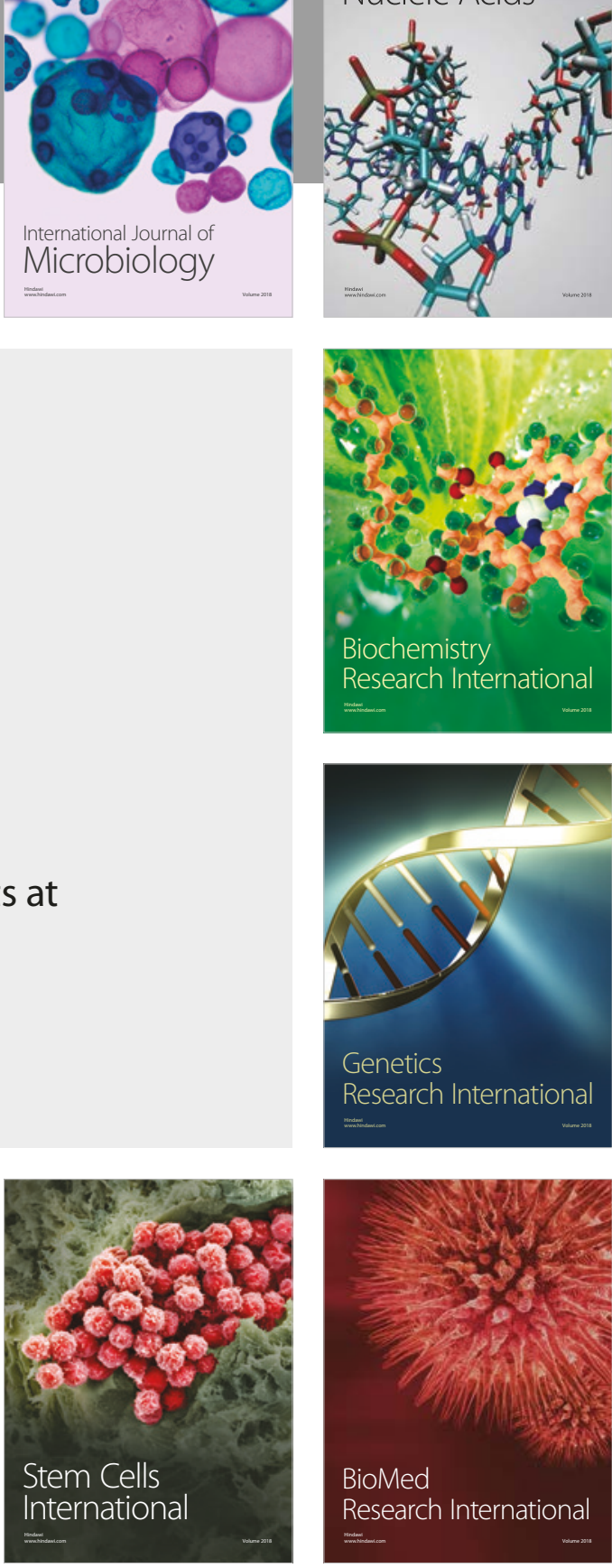
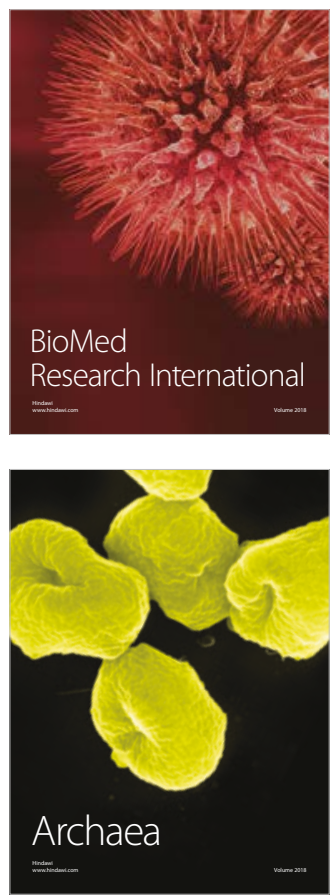